by enzyme-like polymers are covered by $\mathrm{T}$. Kunitake, and those of transition metals by C.V. Pittman Jr. Chapter 6, on synthesis using polymer-supported protecting groups, by J.M.J. Fréchet, includes asymmetric synthesis and preparation of alkaloids, unsymmetrical carotenoids and other interesting syntheses. A sober and thorough assessment of the present scope and limitations of polymer-supported synthesis in general concludes this chapter. The contributions of J.M. Stewart, Fréchet and M.J. Gait describe solid-phase synthesis of peptides, oligosaccharides and oligonucleotides, respectively. Although the peptide and nucleotide topics have been reviewed frequently and in more detail elsewhere, these three skilfully prepared chapters are well worth reading. Solid- phase oligosaccharide synthesis still needs much work to become competitive. Completing the main text is another chapter by Hodge, on various applications of polymer-supported species. Rounding off the book is an appendix which provides experimental guidance on the art of suspension polymerization, and on chemical modification of polymers.

This useful book gives thorough attention to detail and provides a wealth of clearly drawn illustrations. Research into polymer-supported reactions is a young and growing enterprise. This book should certainly further its development.

Johannes Meienhofer is in the Chemical Research Department of Hoffmann-La Roche, Inc., Nutley, New Jersey, USA.

\title{
Of plants and pathogens
}

\section{John Friend}

Plant Disease: An Advanced Treatise. Vol. 5, How Plants Defend Themselves. Edited by James G. Horsfall and Ellis B. Cowling. Pp.534. ISBN 12-356-4050. (Academic: 1980.) £27.80, $\$ 49.50$.

Plants have a range of natural defences which enable them to grow successfully and produce healthy crops despite the widespread presence of many potential pathogens. These resistance mechanisms have had an impact on plant evolution and further understanding of the processes is required in order that the mechanisms can be utilized and adapted by plant breeders and agronomists to improve crop production and yield.

In How Plants Defend Themselves, the final volume of a multi-author treatise on plant disease, the various ways in which plants resist disease are covered in 23 chapters. The early sections cover welldocumented resistance phenomena such as escape from, and tolerance to, disease.

Later contributions deal with preformed barriers to attack, both physical and chemical. Physical barriers may be external, such as specialized types of plant surfaces and their coverings, or internal, including suberized and lignified tissues, gums, resins and silica. Preformed defensive chemicals include relatively simple compounds exuded from roots and specific antifungal and antibacterial compounds, often of chemotaxonomic interest, present inside the plants.

Considerable effort is now being expended on research into active mechanisms of plant resistance to pathogens, a topic which is covered in considerable depth in the book. Recognition and compatibility between host and parasite which are the most important initial events are surveyed in detail by Sequeira, who pays particular attention to the possible functions of lectins, polysaccharides and lipopolysaccharides. Király reviews hypersensitivity with particular reference to his own recent experiments, and concludes that it is not necessarily the cause of resistance but probably a result of stress that develops in incompatible host-parasite combinations. Following a review of active formation of physical barriers by Beckman, Cruickshank provides a thoughtful review of the phytoalexin concept and the possible roles of phytoalexins in disease resistance.

However, the highlight of the book is a series of five chapters on acquired immunity to a second attempted invasion triggered by an initial infection by viruses, bacteria, fungi, nematodes and insects. In the main these chapters are descriptive, but the two on viruses and bacteria discuss possible mechanisms for this type of resistance which could involve alterations in nucleic acid and protein metabolism.

The phenomena are of great importance for an understanding of resistance mechanisms and may also have practical application in the design of new fungicides.

The book is an excellent summary of the most recent work on plant disease resistance. It can be criticized because it under-emphasizes the stimulus given by plant pathologists to research on the biochemistry and physiology of healthy plants; nevertheless, the reader should realize that the editors deliberately tried to produce a series in which the authors would write reflective articles examining the future of research on plant disease. Despite the rather anthropomorphic chapter headings and the idiosyncratic suggestion that plant resistance is analogous to the defence of a mediaeval castle, this editorial policy has been successful.

John Friend is Head of the Department of Plant Biology at the University of Hull.
Nature's archives

\section{Robert Olby}

Natural History Manuscript Resources in the British Isles. Compiled by G.D.R. Bridson et al. Pp.473. ISBN 0-7201-1559 -0. (Mansell, London/Bowker, New York: 1980.) $£ 97$.

EVER since the establishment and consolidation of local government authorities in the nineteenth century, archive material has been preserved in provincial record offices, public libraries and civic universities on an increasing but uncoordinated basis. Successive parliamentary acts have expanded the list of official repositories for public documents, most of which are held either in a record office under the jurisdiction of the chief executive (formerly the town clerk) or in a public library under the control of the librarian. The scattering of archives between public libraries, record offices, museums, local societies, professional institutions and universities is inevitable given the varied sources generating them and the diversity of the parties interested in studying them. That the reform of local government in 1974 failed to clarify the relationship between the record office and public library is hardly surprising. That there should be some rivalry between civic universities and public libraries over the deposit of documents is to be expected. The important problem is that of guiding the inquirer in his search for source material.

There have been a number of initiatives to offer such guidance and to stimulate the formation of collaborative policy for deposition. The Commission on Historical Manuscripts, which celebrated its centenary in 1969, has played an invaluable role through the National Register of Archives which was established in 1949. Of particular importance for the history of science is the work of the Contemporary Scientific Archives Centre at Oxford.

The initiative for the present work goes back to the 1960 s when D.E. Allen, R.H. Ellis and others formulated an ambitious plan to conduct a major search of the country's archives which relate to natural history. In the event adequate funds were not forthcoming and a more modest survey was undertaken by Bridson, Phillips and Harvey. They are to be congratulated for the extent and the detail of their book. There have always been close links between botany, zoology and natural history. Since the beginning of this century experimental biology has distanced itself from the work of the naturalists, but for most of the period covered by this survey students should find this book an aid to research. The only regret is that the authors were unable to include the extensive collections of the Public Record Office at Kew.

Robert Olby is Reader in the History of Science, Department of Philosophy, University of Leeds. 